\title{
Dietary sources of vitamin D in school children in Northern Ireland
}

\author{
H. Benson ${ }^{1}$, D.U. Glatt ${ }^{1,2}$, L. Beggan ${ }^{1}$, E.M. McSorley ${ }^{1}$, L.K. Pourshahidi ${ }^{1}$, J. McCluskey ${ }^{2}$, \\ R. Revuelta Iniesta ${ }^{3}$, N. Gleeson ${ }^{2}$ and P.J. Magee ${ }^{1}$ \\ ${ }^{1}$ Nutrition Innovation Centre for Food and Health (NICHE), Ulster University, Coleraine, UK, \\ ${ }^{2}$ Department of Dietetics and Nutrition, Queen Margaret University, Edinburgh, UK and \\ ${ }^{3}$ Department of Sports and Health Sciences, University of Exeter, Exeter, UK
}

This abstract was awarded the student prize.

The primary sources of vitamin D are epidermal vitamin D synthesised via UVB exposure and dietary sources from oily fish, meat and fortified foods and supplements ${ }^{(1)}$. In Northern latitudes $\left(>37^{\circ}\right)$, between September and March, sun exposure is insufficient to synthesise enough vitamin D, and dietary sources including the use of supplements, are important to meet requirements ${ }^{(1)}$. The UK government currently recommends a $10 \mu \mathrm{g} / \mathrm{day}$ vitamin $\mathrm{D}$ supplement for children to maintain vitamin $\mathrm{D}$ status from October to March $^{(1)}$. The reference nutrient intake (RNI) for vitamin D is $10 \mu \mathrm{g} /$ day; however, current mean(SD) intake is $4.2(3.1) \mu \mathrm{g} / \mathrm{day}^{(2)}$ and only $10 \%$ of children take a vitamin D containing supplement ${ }^{(3)}$.

This study investigates dietary sources of vitamin D in a convenient sample of school children in Northern Ireland. Secondary analysis investigated the relationship between age and vitamin D intake. Forty-four children were recruited between November 2019 and March 2020 as part of a larger study. Height and weight were measured, and daily vitamin D intake and consumption of vitamin D rich foods were assessed via a six-month retrospective food frequency questionnaire $(\mathrm{FFQ})^{(4)}$.

The study cohort had a mean age of $8.1 \pm 2.1$ years and $64 \%(28)$ were female. Mean(SD) height was $1.3(0.1) \mathrm{m}$, mean(SD) weight was $32.2(12.2) \mathrm{kg}$ and the children's mean(SD) body mass index (BMI) was 17.6(3.2) $\mathrm{kg} / \mathrm{m} 2$. Mean(SD) dietary vitamin D intake, derived from the FFQ and including vitamin D supplement contribution, was 6.4(5.6) $\mu \mathrm{g} / \mathrm{day}$. Vitamin D intakes of children taking a vitamin D supplement $(8,18 \% ; 16.5 \pm 4.3)$ were significantly higher than those not taking a supplement $(36,82 \% ; 4.2 \pm 2.5), \mathrm{p}<$ $0.001 ; 95 \% \mathrm{CI}$ ). There was no difference in vitamin D intake between boys and girls. The top five contributing food groups were as follows: breakfast cereals $(1.3(1.0) \mu \mathrm{g} / \mathrm{day})$, fish $(1.0(1.2) \mu \mathrm{g} / \mathrm{day})$, spreads $(0.6(0.6) \mu \mathrm{g} /$ day $)$, meat $(0.5(0.6) \mu \mathrm{g} / \mathrm{day})$ and eggs $(0.5$ $(0.5) \mu \mathrm{g} / \mathrm{day})$. Age (years) was negatively correlated with vitamin $\mathrm{D}$ intake $(\mu \mathrm{g} / \mathrm{day})(\mathrm{rs}=-0.36, \mathrm{p}=0.02)$ and supplement intake $(\mu \mathrm{g} / \mathrm{day})(\mathrm{rs}=-0.32, \mathrm{p}=0.033)$.

Mean dietary vitamin D intake in this cohort was below the current recommendation, whereas those children who were taking a supplement met the daily recommendation. The food groups that contributed the most towards total vitamin D intake were vitamin D-containing supplements, fortified breakfast cereals, fish, meat, and eggs. Future public health messages need to focus on promoting vitamin D rich foods, including fortified foods, in addition to highlighting the importance of supplementation, particularly during the winter months. Mandatory vitamin D food fortification may need considered.

\section{References}

1. Scientific Advisory Committee on Nutrition (SACN) (2016) [Available at: gov.uk/government/publications/sacn-vitamin-d-and-health-report]

2. Irish Universities Nutrition Alliance (IUNA) (2019) [Available at:iuna.net/surveyreports]

3. Public Health England (2019) National Diet and Nutrition Survey [Available at: gov.uk/government/statistics/ndns-results-from-years-9to-11-2016-to-2017-and-2018-to-2019]

4. Weir RR, Carson EL, Mulhern MS, et al. (2016) J Hum Nutr Diet 255-61 